\title{
INETRDISCIPLINARY CURRICULUMN: GROWING NEEDFOR HIGER EDUCATION SYSTEMS
}

\author{
A. Baishya, M.Tech. \\ Tezpur University, India
}

\begin{abstract}
This paper presents a brief review of interdisciplinary curriculum design and its challenges and opportunities in the context of higher education systems. A brief description to curriculum design in general leading to content design for interdisciplinary curriculum has been incorporated. The main purpose of this paper is to define curriculum integration, issues related to interdisciplinary curriculum design and integration, present the popular interdisciplinary curriculum and discuss the challenges and present the important implications curriculum integration will have on education.
\end{abstract}

Keywords: Interdisciplinary, Disciplinary, Multi-disciplinary, Crossdisciplinary, Trans-disciplinary

\section{Introduction}

Academic curriculum is a dynamic phenomenon that must be capable of recognizing the changes in the environment and respond to the growing demands and challenges. Education is a large system and it is nearly impossible to predict its behavior over distant future since the system parameters show a high rate of change. Mobility of professionals across the national boundaries has changed the demand-supply perspective and this may eventually force the educational planners to take a global view. Careful extrapolation of these and other relevant inputs may permit us to predict the near future behavior of the education systems. However, predictions over medium or long ranges are difficult primarily because of the involvement of a large number of fuzzy parameters.

In order to make the current higher education systems more relevant and career-oriented with focus on quality and excellence, higher educational institutions around the world need to re-orient and reshape their programs and policies. It is envisaged that professionally qualified graduates with a sound knowledge of interdisciplinary studies will have more opportunities in higher academic institutions and employment sectors in the years to come. 
Demand and scope for such professionally trained interdisciplinarians are visible in the applied fields in the changing complex global scenario and is likely to increase in the future. Consequent upon the need of reorientation and reshaping of academic programs, many institutions of higher learning either have already started redesigning/ reorientation of their curricula while many are perhaps in their planning phases. Preliminary survey of such programs reveals that in many occasions, the interdisciplinary curriculum designers put their best efforts with all good intentions but fails to attract large number of students and faculties because of lack of focus and welldefined curriculum objectives. It may also be observed that many interdisciplinary curricula are not perfectly interdisciplinary, rather multidisciplinary or trans-disciplinary. It is also not rare to see interdisciplinary curriculum where the content is merely a sampling of knowledge of the constituent disciplines.

\section{Why Interdisciplinary Curriculum?}

There exist various important as well as complex real world problems, phenomena and concepts that can not be clearly understood or resolved when approached from a single discipline. While disciplinary depth is considered to be a must for investigating these complex issues, they also require what Howard Gardner calls a 'synthesising mind' (2006). These issues demand investigators competent to engage themselves as a part of team or individually, in order to develop a complete resolution that would have not been possible from a single discipline. Lyon (1992) and Brew (2008) show that this is not a deviant exception, but a common path for the modern academics.

Educational researchers have opined that an integrated curriculum is more likely to result in greater intellectual curiosity, improved attitude towards schooling, enhanced problem-solving skills, and higher achievement in college (Austin, Hirstein, \& Walen, 1997; Kain, 1993). Barab and Landa (1997) indicated that when students focus on problems worth solving, motivation and learning increase. And one of the best ways to promote problem solving is through an enriched environment that makes connections among several disciplines (Wolf \& Brandt, 1998).

The implication is that universities and other institutions of higher learning need to design academic curriculum to impart education simultaneously in both disciplinary as well as interdisciplinary expertise

\section{What is Interdisciplinary Curriculum?}

"The very notion of 'integration' incorporates the idea of unity between forms of knowledge and the respective disciplines" (Pring, 1973). 
In Jacobs' (1989) definition, interdisciplinary means conscientiously applying methodology and language from more than one discipline to a theme, topic, or problem.

The interdisciplinary approach has been defined by William $\mathrm{H}$. Newell and William Green (1982) as "inquiries which critically draw upon two or more disciplines and which lead to an integration of disciplinary insights" (Haynes, 2002).

Although several variants of the definition of interdisciplinary studies have recently been emerged the version proposed by Allen Repko (2008) is the most accepted one. He identifies a ten-part interdisciplinary process that culminates in a deconstruction of interdisciplinary integration: identify conflicts between insights; create common ground; integrate insights; and produce and test an interdisciplinary understanding of the problem.

Many educators represent the view that knowledge in interdisciplinary studies is a repackaging and, perhaps, enhancement of discipline-based knowledge (Kain, 1993). The following example will probably give a more clear insight of interdisciplinarity. The chemist Willard Libby who discovered radiocarbon dating, applied his findings in chemistry to the discipline of archeology and won the Nobel Prize in 1960 (Youngblood, 2007).

To ensure a holistic understanding of interdisciplinarity, it is imperative that one should also understand the other disciplinary variants very often mistaken for one another. The different scientific orientations of disciplinarity along with their definitions are depicted in Table-1.

The interdisciplinary approach is uniquely different from a multidisciplinary approach, which is the teaching of topics from more than one discipline in parallel to the other, nor is it a cross-disciplinary approach, where one discipline is crossed with the subject matter of another. An interdisciplinary curriculum may therefore be closely related to an integrated curriculum.

\begin{tabular}{|c|c|}
\hline $\begin{array}{c}\text { Scientific } \\
\text { orientation }\end{array}$ & Definition \\
\hline $\begin{array}{c}\text { Uni__ } \\
\text { disciplinarity } \\
\end{array}$ & $\begin{array}{l}\text { One discipline works to address the problem intended } \\
\text { for. }\end{array}$ \\
\hline $\begin{array}{l}\text { Cross__ } \\
\text { disciplinarity }\end{array}$ & $\begin{array}{c}\text { Two or more disciplines work side-by-side without mutual } \\
\text { involvement to solve their problems. Disciplinarians are confined } \\
\text { within their disciplines only. }\end{array}$ \\
\hline $\begin{array}{l}\text { Multi__ } \\
\text { disciplinarity }\end{array}$ & $\begin{array}{l}\text { Two or more disciplines work independently on a common } \\
\text { problem. There is little or no commonality in terminology and } \\
\text { methodology to address the problem. Practitioners work within } \\
\text { their discipline but recognize that there exist different facets to a } \\
\text { common problem. }\end{array}$ \\
\hline
\end{tabular}




\begin{tabular}{|c|c|}
\hline $\begin{array}{c}\text { Trans__ } \\
\text { disciplinarity }\end{array}$ & $\begin{array}{c}\text { Two or more disciplines work together on a common problem with } \\
\text { some overlap in methodology and terminology. Some integration } \\
\text { between disciplines is likely to occur leading to common concepts, } \\
\text { potentially new models and theories, but there is no complete } \\
\text { overlap. Practitioners still feel mostly confined to their traditional } \\
\text { disciplines }\end{array}$ \\
\hline $\begin{array}{c}\text { Inter_ } \\
\text { disciplinarity }\end{array}$ & $\begin{array}{c}\text { Two or more disciplines work integrally on a common problem. } \\
\text { Disciplines are synthesized and extend discipline-specific theories } \\
\text { and concepts with potentially novel methodology that is relevant to } \\
\text { all involved disciplines. Practitioners feel at ease in all the involved } \\
\text { disciplines. }\end{array}$ \\
\hline
\end{tabular}

Table-1. An overview of definitions used to classify scientific orientation, based on (Rosenfield, 1992; Stokols et al., 2008).

\section{Challenges and Opportunities}

The design of any curriculum for such a dynamic system is a very challenging task. Further difficulties arise when the multifarious nature of interdisciplinarity functions - each requiring differing skills, abilities and attitudes are needed to be brought into consideration.

Interdisciplinary courses are primarily intended to reflect the linkages and interdependencies among subjects, disciplines, and courses and the associated concepts, skills, and applications, and are perhaps much more than the sum of the disciplines included in a curriculum. Interdisciplinary education also needs to supplement disciplinary teaching and learning so that students can learn to respond to challenges that go beyond disciplines, work in the confluence of multiple disciplines, and develop research trajectories that do not conform to standard disciplinary paths. Interdisciplinary education should also go beyond the above goals by allowing students to see different perspectives, work in groups, and make them competent to synthesize various disciplines as their ultimate goal.

As the interdisciplinary approach continues to synthesize the characteristics and methods of multiple disciplines while developing lifelong learning skills, they will have met the goals that Newell (1982) has laid out. Interdisciplinary curricula is time consuming and takes collaborative team work to create, which is undoubtedly hard and exhausting, but results in many skills that are sought by future employers. Also the students and their teachers will advance themselves in critical thinking, communication, creativity, pedagogy, and essential academia with the use of interdisciplinary techniques.

The students of interdisciplinary curriculum are expected to gain fluency in the ideas and languages of various constituent disciplines and also in the behaviors expected from various disciplinary communities. This is considered to be the unique challenge to an interdisciplinary curriculum. Interdisciplinary students and scholars very often confront the need for 
fluency in multiple fields which results in conflicts between the idealized and enacted interdisciplinary curriculum. The interdisciplinary curriculum is delivered in disciplinary organizations, the universities where disciplinary ways of thinking and behaving prevails and it is , therefore, very difficult to accomplish interdisciplinary ways of thinking and behaving. Again, it is very likely that the teachers delivering the interdisciplinary curriculum are trained in a disciplinary field. These challenges need special organizational and pedagogical strategies.

Interdisciplinary teaching and learning is a challenge to both teachers and students (Woods, 2007; Bleakley et al., 2011). Teachers are often specialized in a particular discipline and find it difficult as well as challenging to engage themselves with other teachers, as there is lack of a common vocabulary and educational vision. However, it is this competence in communication between disciplines that is at the heart of interdisciplinary teaching (Woods, 2007).

It is very difficult to design interdisciplinary course curricula because of the reasons like student prerequisite and academic respect which is a function of previous observations. Students enrolled in an interdisciplinary program face lots of difficulties to adjust to a new field having broad and shifted boundaries. Also it is very difficult to get prerequisites in all the constituent disciplines of an interdisciplinary program without which it is likely to be rejected by both the practitioners as well as students of individual component disciplines. Moreover, any undergraduate curriculum has the requirement to train the students in a broad field rather than specializing in a too narrower field of study. Most of the unsuccessful interdisciplinary curricula are found to fail because of lack of these technical issues.

Preliminary survey of various models and approaches to interdisciplinary curriculum design reveals that many interdisciplinary courses were planed with good intentions but failed due to the following problems associated with content selection (Jacob, 1989):

The Potpourri Problem- This problem arises when many units become a sampling of knowledge from each of the constituent discipline. Hirsch (1987) and Bloom (1987) have criticized this approach for its lack of focus. While discipline based curriculum have an inherent scope and sequence, there is no apparent scope and general structure in interdisciplinarycurriculum. Curriculum planners and developers have to design the content scope and sequence very carefully for interdisciplinary courses.

The Polarity Problem: The discipline fields and the interdisciplinarity have been so far seen as an either/or polarity which resulted in a series of conflicts such as lack of clarity, threat to teachers who 
are highly territorial about their disciplines as interdisciplinary curriculum promotes new views of their subjects.

In view of the above, it may be concluded that the interdisciplinary curriculum needs to incorporate interdisciplinary as well as disciplinary field perspectives in the curriculum design since the goal of an interdisciplinary curriculum is to train future scholars and practitioners who can bridge multiple disciplines in their work.

Most of the academic systems around the world are still very much structured as far as concentration of specific cores as disciplines are concerned and the integration of interdisciplinary studies have become unusual to the traditional fields of study. Most of the existing education systems suffer from rigidness (F.Gider et al, 2012) and therefore unable to follow frequent changes in order keep pace with modern world demand. A change in orientation of the course curriculum from knowledge towards competencies along with strong emphasis in innovation is needed in order to generate human resource with leadership quality and professionalism in order to meet global competition requirements. We therefore, need to reorient the existing performance criteria-driven alignment and integration of course curricula to competency based curricula particularly while designing competency-based interdisciplinary curricula.

It is, therefore, important to develop a conceptual framework in which students can be taught interdisciplinary, rather than multidisciplinary thinking. The ten generic points in curriculum design proposed by Kirkpatrick and stated below may be taken into consideration in the design of the interdisciplinary curriculum.

- Establishing the learning needs

- Defining learning objectives

- Determine an appropriate subject content

- Selecting participants

- Determining the best schedule

- Selecting appropriate facilities

- Selecting appropriate instructors

- Selecting and preparing audio-visual aids

- Coordinating the program

- Evaluating the program

Prior to designing the curriculum, communication between the different actors such as university administrators, course designers and coordinators, teachers and prospective students is important, as aims, objectives and learning outcomes will be the most important factors that define the learning process in a top-down fashion (Prideaux, 2003).

According to Newell (1983) "best undergraduate education asks students to go back and forth between disciplinary and interdisciplinary 
courses, since interdisciplinary courses need the disciplines for depth and disciplinary courses need interdisciplinarity for real-world applicability".

Interdisciplinary studies need to be conceived in a way that values diversity of perspective, demands integration of insights, and embraces holistic as well as reductionist thinking. Only then are students prepared to meet the challenge of coping with complexity (Newell, 2010)

\section{Conclusion}

Whether a curriculum is interdisciplinary or multi-disciplinary should not be the main issue. Rather, the focus should be on designing a curriculum that is relevant, standards-based, and meaningful for students and future employers. At the same time, the curriculum should be able to make the students competent to solve real world problems. An interdisciplinary curriculum appropriately conceived and well grounded in constituent academic disciplines is expected to deliver the most effective education for the complex future world ahead.

\section{References}

J. D. Austin, J. Hirstein, \& S.Walen, (1997). Integrated mathematics interfaced with science. School Science and Mathematics, 97(1), 45-49.

S.A. Barab, \&A.Landa, (1997). Designing effective interdisciplinary anchors. Educational Leadership. 54(6), 52-58.

A. Bleakley, M. Hennessy, M .Fishbein, A. Jordan (2011). Using the integrative model to explain how exposure to sexual media content influences adolescent sexual behavior. Health Educ Behav 38:530-540.

A. Bloom(1987). The Closing of the American Mind. New York: Simon and Schuster.

A. Brew (2008). Disciplinary and interdisciplinary affiliations of experienced researchers. Higher Education, 56(4), 423-438.

H. Gardner (2006). Five Minds for the Future. Boston, Mass.: Harvard Business School Press.

F.Gider, B.Likar, T.Kern, and D.Miklavcic (2012) "Implementation of a multidisciplinary professional skills course at an electrical engineering school,” Education, IEEE Transactions on, vol. 55, no. 3, pp. 332-340.

E.D.Jr. Hirsch (1987). Cultural Literacy. Boston: Houghton-Mifflin.

H. H.Jacobs(1989). Interdisciplinary curriculum: design and implementation. Alexendria, Edwards Brothers, Inc.

D. L. Kain(1993). Cabbages and kings: Research directions in integrated/ interdisciplinary curriculum. The Journal of Educational Thought, 27(3), 312-331.

D.L. Kirkpatrick.( 1994). Evaluating training programs. San Francisco, CA: Berrett-Koehler. 
A. Lyon (1992). Interdisciplinarity: Giving up Territory. College English, 54(6), 681-693.

W.H. Newell and W. J Green. Dejzing and Teaching Interduciplinary Srudier. Improving College and University Teaching 30.1 (1982), 23-30.

W.H. Newell (1983). The Role of Interdisciplinary Studies in the Liberal Education of the 1980. Liberal Education 69 (3): 245-55.

W.H. Newell (2010) Educating for a Complex World: Integrative Learning and Interdisciplinary Studies. Liberal Education, Vol. 96, No. 4.

D. Prideaux (2003). ABC of learning and teaching in medicine - Curriculum design. Br Med J.;326:268-270.

R. Pring, (1973). Curriculum integration. In R. S. Peters (Ed.), The philosophy of education (pp. 123-149). London: Oxford University Press.

Allen F. Repko, (2008). Interdisciplinary Research: Process and Theory. Thousand Oaks, CA: SAGE Publications.

P.L. Rosenfield (1992) The potential of transdisciplinary research for sustaining and extending linkages between the health and social sciences. Soc Sci Med 35:1343-1357.

D. Stokols., K.L., Hall, B.K. Taylor and R. P. Moser (2008) The science of team science: overview of the field and introduction to the supplement. Am J Prev Med 35:S77-S89.

P., Wolf and R.Brandt, (1998). What do we know from brain research? Educational Leadership, 56(3), 8-13.

C. Woods (2007). Researching and developing interdisciplinary teaching: towards a conceptual framework for classroom communication. Higher Education 54:853-866.

Dawn Youngblood, (2007). Interdisciplinary Studies and the Bridging Disciplines: A Matter of Process. Journal of Research Practice, v.3, i.2. 